\title{
Research on Multi-target Directional Disassembly of Products Based on Ant Colony Algorithm
}

\author{
Weike Chen ${ }^{1, *}, \mathrm{Yu} \mathrm{Liu}{ }^{2}$, Tan Wang ${ }^{3}$ and Dong Xiang ${ }^{3}$ \\ ${ }^{1}$ The College of Information Science and Technology of Beijing Normal University, Beijing 100875, China \\ ${ }^{2}$ SICHUAN CHANGHONG ELEC CO., LTD, Mianyang 621000, China \\ ${ }^{3}$ Dept of Mechanical Engineering of Tsinghua University, Beijing 100084, China \\ ${ }^{*}$ Corresponding author
}

\begin{abstract}
In view of the green manufacturing and remanufacturing product disassembly planning problem, one disassembly sequence planning method based on mixed graphs model of single entry specific target set is put forward, all possible disassembly sequences are generated through the construction of specific target disassembly album mixed graphs, using ant colony algorithm for disassembly mixed graphs, evaluating comprehensive cost through the heuristic information. The feasibility of the model and algorithm is verified through specific product disassembly example.
\end{abstract}

Keywords-directional disassembly; mixed graphs; ant colony algorithm; sequence planning

\section{INTRODUCTION}

Modern manufacturing is no longer only based on direct manufacturing efficiency and manufacturing cost competition, more constraint of limited resources and environmental constraints should be considered, so green manufacturing and remanufacturing gradually become the mainstream of the development of modern manufacturing industry as a kind of comprehensive consideration of environmental impact and resource efficiency of advanced manufacturing mod. However, how to disassemble efficiently, orderly, contrapuntally, recycling and reusing the effective implication resources become one of the key problems to be solved in the modern manufacturing industry development as a kind of advanced manufacturing mode, facing the old products with the variety, complex structure, the different requirement.

To solve this problem, many scholars have made a lot of research such as in [1] propose a method of disassembly sequence generation based on modularization, build a modular product disassembly model, automatically generate the level network graph of products, and analyzed precedence constraints according to the hierarchy network graph, in [2] plan part motion based on the rapidly random expansion tree algorithm of adaptive dynamic multi tree, in [3] describes the concept of disassembly feasibility information graph, transforming the problem of disassembly sequence planning into the optimization problem with weighted and optimum path search to the graph, and then plan the disassembly sequence of product, reference [4] put forward one method of combining disassembly mixed graphs and particle swarm algorithm, realizing the fast solution of complex product object selective disassembly sequence optimization, in [5] search for optimal or closely optimal single object selective disassembly sequence based on mixed graphs model and particle swarm algorithm, regarding its individual parts a the goal. The above research confine to the overall steps of the disassembly according to disassembly optimal judgment, they resolve the complete deconstruction and disassemble of the products without directional selectivity.

In fact, the goal of products disassembly involved green manufacturing and remanufacturing are implemented mainly by recovery of a specific part. Therefore, this paper puts forward one method starting from the single entry and disassembling products in particular multiple target parts through the improved ant colony algorithm, which is based on mixed graph model, regards product disassembly cost and time comprehensive cost as the standard.

\section{Product Disassembly Mixed Graph Mode}

The product disassembly mixed graph[6] model in this paper is projected into the directed diagram and no directed graph set by product structure model, which is composed of directed edges, no directed edge and vertex. The three parts respectively carry three kinds of information related to disassembly. Vertices are defined by parts of disassembly product and sub assemblies, directed edges limit disassembly sequence between the different components and sub assembly, undirected edges represent relationship between all the parts and assembly. The assembly of mouse is as shown in Figure I, which can be projected into the mixed graphs as shown in Figure II.

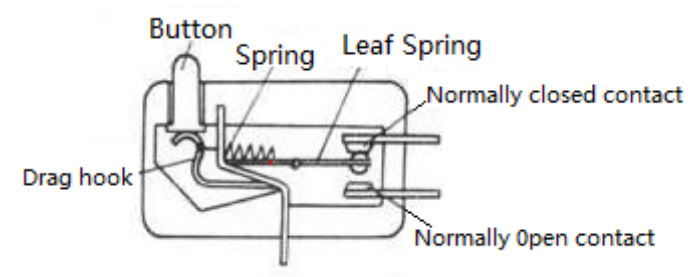

FIGURE I. ASSEMBLY DRAWING

Figure II the vertex $\mathrm{V}_{0}$ is shell, vertex $\mathrm{V}_{1}$ is operating knob, vertex $V_{2}$ is retractor, vertex $V_{3}$ is spring, vertex $V_{4}$ is moving spring reed, vertex $V_{5}$ is normally closed contact; vertex $V_{6}$ is the normally open contact.

Disassembly mixed graph is shown as $\mathrm{P}=\{\mathrm{V}, \mathrm{UE}, \mathrm{DE}\}$, where $p$ is product to be disassembled, UE is no directional edge collection, on behalf of associated constraints between two parts or sub assemblies. DE is directional edge collection, 
on behalf of disassembly sequence between parts or sub assemblies, for example, the arrow between vertex $V_{0}$ and $V_{2}$ in Figure II means part 0 should be disassembled before part 2, while the mixed graph can be represented by two adjacency matrices.

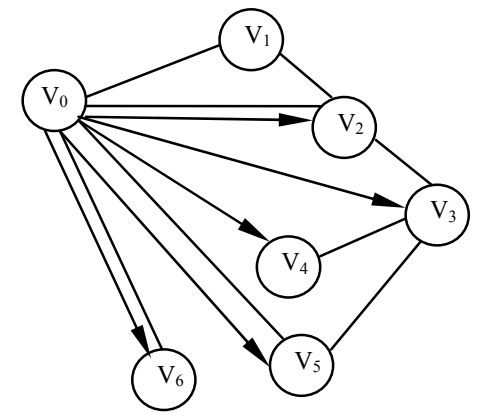

FIGURE II. DISASSEMBLY MIXED GRAPH MODEL OF PRODUCTS

$$
U E=\left\{u e_{i, j}\right\}=\left[\begin{array}{ccccc}
u e_{1,1} & u e_{1,2} & u e_{1,3} & \ldots & u e_{1, n} \\
u e_{2,1} & u e_{2,2} & u e_{2,3} & \cdots & u e_{2, n} \\
u e_{3,1} & u e_{3,2} & u e_{3,3} & \ldots & u e_{3, n} \\
\vdots & \vdots & \vdots & \vdots & \vdots \\
u e_{n, 1} & u e_{n, 2} & u e_{n, 3} & \cdots & u e_{n, n}
\end{array}\right]
$$

where:

$$
\begin{gathered}
\text { ue }_{i, j}= \begin{cases}1 & \text { part } \mathrm{i} \text { is connected to part } \mathrm{j} \\
0 & \text { part } \mathrm{i} \text { is not connected to part } \mathrm{j}\end{cases} \\
\text { when } \mathrm{i}=\mathrm{j}, \quad \mathrm{ue}_{\mathrm{i}, \mathrm{j}}=0 \\
\mathrm{D} E=\left\{\mathrm{d} e_{\mathrm{i}, \mathrm{j}}\right\}=\left[\begin{array}{ccccc}
\mathrm{d} e_{1,1} & \mathrm{~d} e_{1,2} & \mathrm{~d} e_{1,3} & \ldots & \mathrm{d} e_{1, n} \\
\mathrm{~d} e_{2,1} & \mathrm{~d} e_{2,2} & \mathrm{~d} e_{2,3} & \cdots & \mathrm{d} e_{2, n} \\
\mathrm{~d} e_{3,1} & \mathrm{~d} e_{3,2} & \mathrm{~d} e_{3,3} & \ldots & \mathrm{d} e_{3, n} \\
\vdots & \vdots & \vdots & \vdots & \vdots \\
\mathrm{d} e_{n, 1} & \mathrm{~d} e_{n, 2} & \mathrm{~d} e_{n, 3} & \cdots & \mathrm{d} e_{n, n}
\end{array}\right]
\end{gathered}
$$

where:

$$
\begin{aligned}
& \mathrm{d} e_{i, j}= \begin{cases}1 & \text { part } \mathrm{j} \text { must be disassembed before part } \mathrm{i} \text { is } \\
0 & \text { part } \mathrm{j} \text { is irrelevant with disassembly sequence of part } \mathrm{i}\end{cases} \\
& \text { when } \mathrm{i}=\mathrm{j}, \quad \mathrm{de}_{\mathrm{i}, \mathrm{j}}=0
\end{aligned}
$$

The two adjacency matrix [7] for the disassembly mixed graph model is obtained by formula (1) and formula (2), it is shown as Figure II.

$$
U E=\left\{u e_{i, j}\right\}=\left[\begin{array}{ccccccc}
0 & 1 & 1 & 0 & 0 & 1 & 1 \\
1 & 0 & 1 & 0 & 0 & 0 & 0 \\
1 & 1 & 0 & 1 & 0 & 0 & 0 \\
0 & 0 & 1 & 0 & 1 & 1 & 0 \\
0 & 0 & 0 & 1 & 0 & 0 & 0 \\
1 & 0 & 0 & 1 & 0 & 0 & 0 \\
1 & 0 & 0 & 0 & 0 & 0 & 0
\end{array}\right]
$$

$$
D E=\left\{d e_{, j}\right\}=\left[\begin{array}{lllllll}
0 & 0 & 0 & 0 & 0 & 0 & 0 \\
0 & 0 & 0 & 0 & 0 & 0 & 0 \\
1 & 0 & 0 & 0 & 0 & 0 & 0 \\
1 & 0 & 0 & 0 & 0 & 0 & 0 \\
1 & 0 & 0 & 0 & 0 & 0 & 0 \\
1 & 0 & 0 & 0 & 0 & 0 & 0 \\
1 & 0 & 0 & 0 & 0 & 0 & 0
\end{array}\right] \quad \text { (4) }
$$

\section{Directional Disassembly Sequence Planning Based on ANT Colony Algorithm FOR Single INLET AND Multi- \\ TARGET PARTS}

Selection probability of ants in ant colony algorithm is decided by the pheromone concentration and the heuristic information [8], and the heuristic information of traditional disassembly method is usually decided by disassembly step number or disassembly difficulty. One effective heuristic information decision method is presented, namely, multiple target parts of product are disposable disassembled, starting from single entry and considering disassembly cost (Mechanical, labor costs) and disassembly time.

\section{A. Heuristic Information and Probability Criterion}

$\mathrm{M}$ is ant population in ant colony,P is disassembly goals set, $\mathrm{D}_{\mathrm{i}}(\mathrm{k})$ is goals collection which has been disassembled for ant $\mathrm{k}$ in point $\mathrm{i}, \mathrm{A}_{\mathrm{i}}(\mathrm{k})$ is goals collection which can be disassembled. The information prime concentration from point $i$ to point $j$ is $\tau(i, j)$, its heuristic information is $(\mathrm{i}, \mathrm{j}), \alpha, \quad \beta$ respectively indicated the weight of information concentration and the heuristic information.

Heuristic information $\eta(i, j)$ is calculated by disassembly cost price $(i, j)$ and disassembly time $(i, j)$, namely, $\eta(i, j)=[m \times \operatorname{price}(i$, $\mathrm{j})+\mathrm{n} \times$ time $(i, j)]^{-\gamma}$, where $m$ is disassembly cost weight, $n$ is disassembly time weight, $\gamma>0, \gamma$ is a constant, price $(i, j)$ is positively related to disassembly cost, time $(\mathrm{i}, \mathrm{j})$ positively related to disassembly time, choice probability $\mathrm{P}_{\mathrm{k}}(\mathrm{i}, \mathrm{j})$ of ant $\mathrm{k}$ based on the above conditions is shown as:

$$
P_{k}(i, j)=\left\{\begin{array}{l}
\frac{\tau(i, j)^{\alpha} \times \eta(i, j)^{\beta}}{\sum_{\mu \in A_{i}(k)} \tau(i, \mu)^{\alpha} \times \eta(i, \mu)^{\beta}} \\
0, j \notin A_{i}(k)
\end{array}, j \in A_{i}(k)\right.
$$

\section{B. Construction of Disassembly Target Set and Update of Pheromone}

Disassembly goals set $A_{i}(k)$ is accessible vertex collection for the ant $\mathrm{k}$ located at point $\mathrm{i}$. The set can be judged by the following steps after the adjacency matrix of the parts in the mixed graph is analyzed:

1)Updating mixed graph,make $\sum_{t=0}^{t=N-1} u e_{i, t}=0$ and $\sum_{t=0}^{t-N-1} d e_{i, t}=0$,namely vertex $\mathrm{i}$ is isolated.

2) If there is a point $\mathrm{j}$ to meet; traversal of all, 
$\sum_{t=0}^{t=N-1} u e_{j, t} \geq 1$ and $\sum_{t=0}^{t-N-1} d e_{j, t}=0$ (there are parts connected with $\mathrm{j}$ and without sequence constraints)in all vertices, $j$ is put into $A_{i}(k)$.

After ant $\mathrm{k}$ pass by $\mathrm{i}-\mathrm{j}$, the local update of the pheromone is shown by the following formula:

$$
\tau(i, j)=(1-\rho) \times \tau(i, j)+\rho \times \Delta \tau(i, j)
$$

where, $0<\rho<1, \rho$ is constant and it is the attenuation coefficient of pheromone;

$\Delta \tau(i, j)$ is pheromone increment that ant $\mathrm{k}$ pass by the path $\mathrm{i}->\mathrm{j}$.

$\Delta \tau(i, j)=\frac{C}{\eta(i, j)}, \mathrm{C}$ is constant, $\eta(\mathrm{i}, \mathrm{j})$ is the normal correlation cost function with disassembly cost price $(i, j)$ and disassembly time $(i, j)$, namely, it is another quantitative characterization to choose the excellent path degree as the heuristic information.

After ants pass by all graphs, the global update of pheromone on each path can be expressed by the following formula:

$$
\tau(i, j)=(1-\rho) \times \tau(i, j)+\rho \times \sum_{k=1}^{m} \Delta \tau_{k}(i, j)
$$

Where, pis the same with the attenuation coefficient of partial update; $\mathrm{m}$ is the number of ant colony involved in of optimization path;

$$
\Delta \tau_{k}(i, j)=\frac{C}{\eta(i, j)} \text { is the pheromone increment that }
$$
the ant $\mathrm{k}$ pass by the path $\mathrm{i}->\mathrm{j}$.

\section{Building Child Mixed Graph And Solving Mixed Graph for} the Specific Objective Collection

When multiple target parts are disassembled directionally in the single entrance, some vertex including disassembly object is built as child mixed graph according to the disassembly target set, and the product mixed graph is solved on this basis.

Step 1: establishing the child mixed graph.

Requirements: if vertex $\mathrm{v}$ collection $\left\{k_{1}, k_{2} \ldots k_{n}\right\}$ meet $i \in\left\{k_{1}, k_{2} \ldots k_{n}\right\} \cap j \in\left\{k_{1}, k_{2} \ldots k_{n}\right\}$;

While $u e_{i, j} \in U E, u e_{i, j}$ will be put into the new matrix UE',

While $d e_{i, j} \in D E, d e_{i, j}$ will be put into the new matrix DE',

Step 2: solving the mixed graph.
The new vertex $n+1$ is generated In the matrix UE, for vertex $i \in\{0 \ldots n\}$,

if $\sum_{t=k_{1}}^{k_{n}} u e_{i, t}=0$,namely, vertex $\mathrm{i}$ is not connected with $\left\{k_{1}, k_{2} \ldots k_{n}\right\}, u e_{i, n+1}=0$ and $u e_{n+1, i}=0$

if $\sum_{t=k_{1}}^{k_{n}} u e_{i, t}=1$, namely, vertex $\mathrm{i}$ is connected with $\left\{k_{1}, k_{2} \ldots k_{n}\right\}, u e_{i, n+1}=1$ and $u e_{n+1, i}=1$.

If $i \in\left\{k_{1}, k_{2} \ldots k_{n}\right\} \cap j \in\left\{k_{1}, k_{2} \ldots k_{n}\right\}$, all points satisfying $u e_{i, j} \in U E$ is deleted.

The new vertex $\mathrm{n}+1$ is generated in the matrix DE, for vertex $i \in\{0 \ldots n\}$,

If $\sum_{t=k_{1}}^{k_{n}} d e_{i, t}=0$, namely, the vertex including $\left\{k_{1}, k_{2} \ldots k_{n}\right\}$ do not need to be disassembled before vertex $\mathrm{i}, d e_{i, n+1}=0$.

If $\sum_{t=k_{1}}^{k_{n}} d e_{t, i}=0$, namely, vertex $\mathrm{i}$ do not need to be disassembled before the vertex including $\left\{k_{1}, k_{2} \ldots k_{n}\right\}$, $d e_{n+1, i}=0$.

If $\sum_{t=k_{1}}^{k_{n}} d e_{t, i}=1$, namely, vertex $\mathrm{i}$ need to be disassembled before the vertex including $\left\{k_{1}, k_{2} \ldots k_{n}\right\}$, $d e_{n+1, i}=0$.

If $\sum_{t=k_{1}}^{k_{n}} d e_{i, t}=1$, namely, the vertex including $\left\{k_{1}, k_{2} \ldots k_{n}\right\}$ need to be disassembled before vertex i, $d e_{i, n+1}=1$.

if $i \in\left\{k_{1}, k_{2} \ldots k_{n}\right\} \cap j \in\left\{k_{1}, k_{2} \ldots k_{n}\right\}$, all points satisfying $d e_{i, j} \in D E$ is deleted.

\section{Product Multi-Target Directional Disassembly Strategy And Ant Colony Algorithm Flow Diagram}

Disassembly strategy is shown as flow diagram Figure III.

The flow diagram of ant colony disassembly algorithm is shown as Figure IV. 


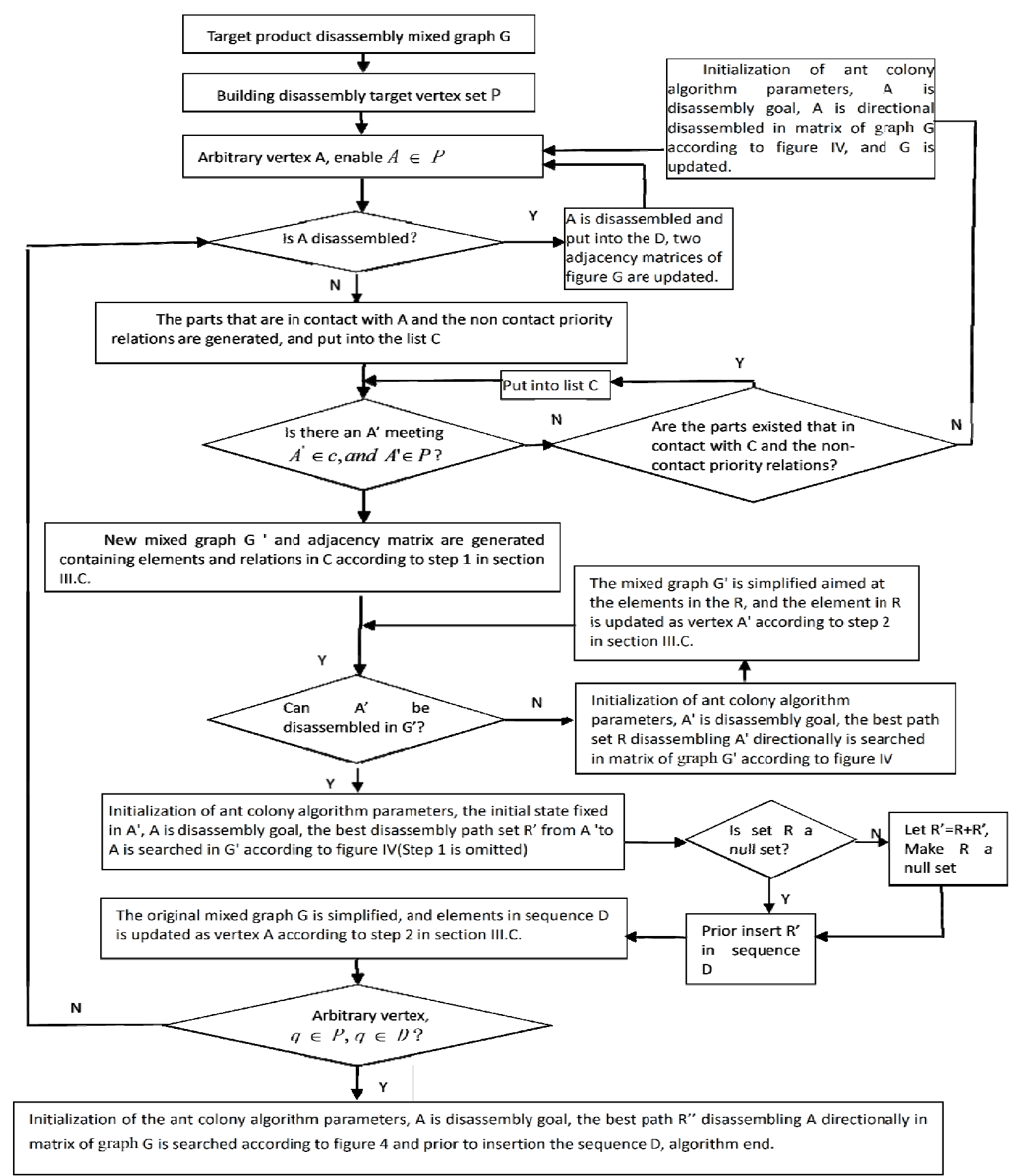

FIGURE III. PRODUCT MULTI-TARGET DIRECTIONAL DISASSEMBLY STRATEGY 


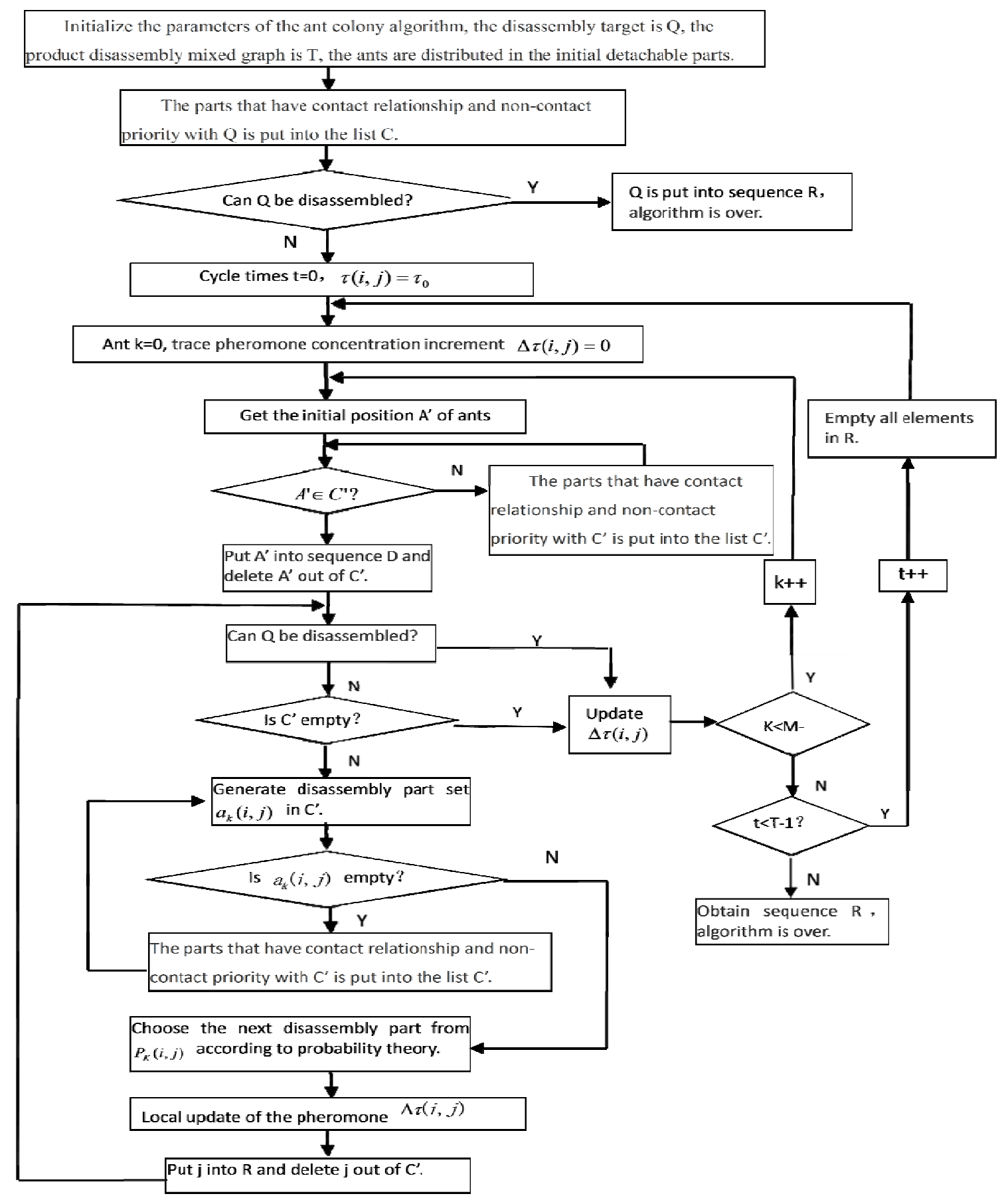

FIGURE IV. THE FLOW DIAGRAM OF ANT COLONY DISASSEMBLY ALGORITHM

\section{EXAMPLE}

The algorithm is verified by disassembling the safety valve, thirteen parts can be disassembled for the safety valve, and the assembly figure is as Figure V. Time and cost that parts are disassembled is shown as Table I.

Three kinds of different disassembly multi-target set is respectively target vertex $\mathrm{P}_{1}, \mathrm{P}_{2}$ and $\mathrm{P}_{3} . \mathrm{P}_{1}=\left\{\mathrm{V}_{9}\right.$ (screw),
$\mathrm{V}_{3}$ (gasket), $\quad \mathrm{V}_{6}$ (nut) $\}, \quad \mathrm{P}_{2}=\left\{\mathrm{V}_{2}\right.$ (valve), $\quad \mathrm{V}_{7}$ (spring), $\mathrm{V}_{12}$ (cover) $\}, \mathrm{P}_{3}=\left\{\mathrm{V}_{3}\right.$ (gasket), $\mathrm{V}_{4}$ (bolt), $\mathrm{V}_{10}$ (nut) $\}$.

The heuristic information $\eta(I, j)=[m \times$ price $(i, j)+n \times$ time $(I$, j)] $\gamma$, weight of unit part disassembly cost $m=0.65$, weight of unit part disassembly time $\mathrm{n}=0.35, \quad \gamma=1$, parameters of ant colony algorithm are as follows: $\alpha=2, \beta=5, \rho=0.6, \mathrm{C}=2$, 
$\tau_{0}=0.25$, the number of a generation of ant colony $\mathrm{M}=32$, iterative $\mathrm{T}=200$.

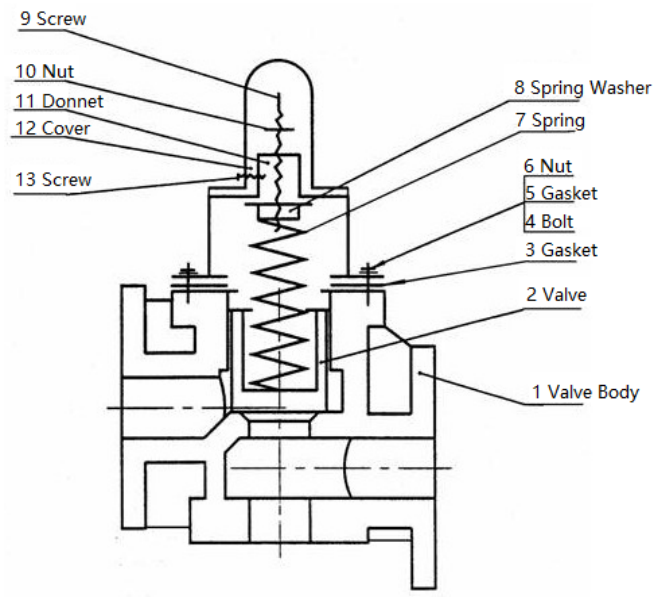

FIGURE V. THE SAFETY VALVE STRUCTURE

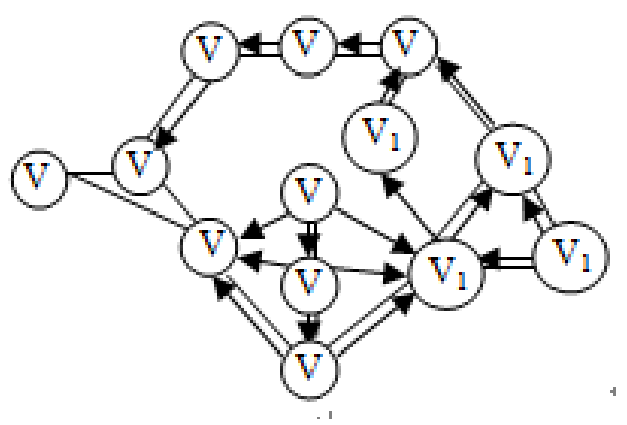

FIGURE VI. THE DISASSEMBLY MIXED GRAPH OF THE SAFETY VALVE

TABLE I. TIME AND COST THAT PARTS ARE DISASSEMBLED

\begin{tabular}{|c|c|c|}
\hline type & Time(min) & Cost(yuan) \\
\hline $\mathrm{V}_{1}$ & 2 & 2 \\
\hline $\mathrm{V}_{2}$ & 1 & 1 \\
\hline $\mathrm{V}_{3}$ & 1 & 1 \\
\hline $\mathrm{V}_{4}$ & 2 & 1 \\
\hline $\mathrm{V}_{5}$ & 1 & 1 \\
\hline $\mathrm{V}_{6}$ & 3 & 2 \\
\hline $\mathrm{V}_{7}$ & 2 & 2 \\
\hline $\mathrm{V}_{8}$ & 1 & 1 \\
\hline $\mathrm{V}_{9}$ & 2 & 2 \\
\hline $\mathrm{V}_{10}$ & 3 & 2 \\
\hline $\mathrm{V}_{11}$ & 1 & 2 \\
\hline $\mathrm{V}_{12}$ & 1 & 2 \\
\hline $\mathrm{V}_{13}$ & 2 & 1 \\
\hline
\end{tabular}

Experimental results show that different local optimal solution is generated according to successively different traversal order in each vertex of $\left\{\mathrm{P}_{1}, \mathrm{P}_{2}, \mathrm{P}_{3}\right\}$, it is as shown in table II, the local optimal solution can ensure consistency of the overall cost, it shows that the algorithm has good convergence.

\section{CONCLUSION}

The strategy of product disassembly planning and optimization algorithm as the common key technologies of green manufacturing and remanufacturing has been a hot issue in academic and industry. In order to solve this problem, this paper proposes one single entrance multi-objective set disassembly strategy based on the mixed graph model, a scientific method that solves the problem of disassembly for disposable product specific target set is provided through building child mixed graph solving disassembly mixed graph for the collection target. The heuristic information is built by the product disassembly cost and time on this basis, and ant colony algorithm is optimized, the example analysis shows this algorithm can effectively search out the optimal path based on incomplete disassembly products and a plurality of specific target parts of disposable disassembly products. The feasibility of theoretical method and the algorithm proposed in this paper is verified.

TABLE II. RESULTS OF ANT COLONY ALGORITHM

\begin{tabular}{|c|c|c|c|c|}
\hline $\begin{array}{l}\text { Target } \\
\text { set }\end{array}$ & $\begin{array}{c}\text { Local optimal solution } \\
\text { sequence }\end{array}$ & cost & time & $\begin{array}{l}\text { Comprehensi } \\
\text { ve cost } \mathrm{H}(\mathrm{i}, \mathrm{j})\end{array}$ \\
\hline \multirow{3}{*}{$\begin{array}{l}\mathrm{P}_{1}=\left\{\mathrm{V}_{9},\right. \\
\left.\mathrm{V}_{3}, \mathrm{~V}_{6}\right\}\end{array}$} & $\begin{array}{l}\text { Local optimal solution 1; } V_{6^{-}} \\
>V_{5^{-}}>V_{4^{-}}>V_{13^{-}}>V_{12^{-}}>V_{10^{-}} \\
>V_{11^{-}}>V_{9^{-}}>V_{3}\end{array}$ & \multirow{3}{*}{14} & \multirow{3}{*}{16} & \multirow{3}{*}{14.7} \\
\hline & $\begin{array}{l}\text { Local optimal solution } 2 ; V_{6^{-}} \\
>V_{5^{-}}>V_{4^{-}}>V_{3^{-}}>V_{13^{-}}>V_{12^{-}} \\
>V_{10^{-}}>V_{11^{-}}>V_{9}\end{array}$ & & & \\
\hline & $\begin{array}{l}\text { Local optimal solution } 3 ; V_{6^{-}} \\
>V_{13^{-}}>V_{5^{-}}>V_{4^{-}}>V_{12^{-}}>V_{10-} \\
>V_{11^{-}}>V_{9^{-}}>V_{3}\end{array}$ & & & \\
\hline \multirow{2}{*}{$\begin{array}{l}\mathrm{P}_{2}=\left\{\mathrm{V}_{2}\right. \\
\left.\mathrm{V}_{7}, \mathrm{~V}_{12}\right\}\end{array}$} & $\begin{array}{l}\text { Local optimal solution 1; } \\
\mathrm{V}_{13^{-}}>\mathrm{V}_{6^{-}}>\mathrm{V}_{5^{-}}>\mathrm{V}_{4^{-}}>\mathrm{V}_{12^{-}} \\
>\mathrm{V}_{10^{-}}>\mathrm{V}_{11^{-}}>\mathrm{V}_{9^{-}}>\mathrm{V}_{8^{-}}>\mathrm{V}_{7^{-}}>\mathrm{V}_{2}\end{array}$ & \multirow{2}{*}{17} & \multirow{2}{*}{19} & \multirow{2}{*}{17.7} \\
\hline & $\begin{array}{l}\text { Local optimal solution } 2 ; V_{6^{-}} \\
>V_{5^{-}}>V_{4^{-}}>V_{13^{-}}>V_{12^{-}}>V_{10^{-}} \\
>V_{11^{-}}>V_{9^{-}}>V_{8^{-}}>V_{7^{-}}>V_{2}\end{array}$ & & & \\
\hline \multirow{3}{*}{$\begin{array}{l}\mathrm{P}_{3}=\left\{\mathrm{V}_{3},\right. \\
\left.\mathrm{V}_{4}, \mathrm{~V}_{10}\right\}\end{array}$} & $\begin{array}{l}\text { Local optimal solution 1; } V_{6^{-}} \\
>V_{5^{-}}>V_{4^{-}}>V_{13^{-}}>V_{12^{-}}>V_{10^{-}} \\
>V_{3}\end{array}$ & \multirow{3}{*}{10} & \multirow{3}{*}{13} & \multirow{3}{*}{11.05} \\
\hline & $\begin{array}{l}\text { Local optimal solution } 2 ; V_{6-} \\
>V_{5^{-}}>V_{4^{-}}>V_{3^{-}}>V_{13^{-}}>V_{12^{-}} \\
>V_{10}\end{array}$ & & & \\
\hline & $\begin{array}{l}\text { Local optimal solution 3; } V_{6^{-}} \\
>V_{13^{-}}>V_{5^{-}}>V_{4^{-}}>V_{12^{-}}>V_{10^{-}} \\
>V_{3}\end{array}$ & & & \\
\hline
\end{tabular}

\section{ACKNOWLEDGMENT}

This paper is supported by National High Technology Research and Development Program of China (863 Program) (Grant No. 2013AA041305).

\section{REFERENCES}

[1] Guo Weixiang, Liu Zhifeng, Liu Guangfu, Pan Xiaoyong, Huang Haihong. Disassembly Sequence Planning Based on Modularization [J]. Journal of Computer Aided Design \& Computer Graphics, 2005, 17(3): 498-504.

[2] ZHAO Boxuan, LIU Jianhua, NING Ruxin, LIU Jiashun. A Motion Planning Based on Selective Disassembly Sequence Planning Method [J]. Journal of Mechanical Engineering, 2014, 50(7):136-145.

[3] WANG Hui, XIANG Dong, DUAN Guang-hong. Product disassembly sequence planning based on ant colony algorithm [J]. Computer Integrated Manufacturing Systems, 2006, 12(9):1431-1437. 
[4] ZHANG Xiufen, ZHANG Shuyou, YI Guodong, LOU Xiyin. Object Selective Disassembly Sequence Planning for Complex Mechanical Products [J]. Journal of Mechanical Engineering, 2010, 46(11):172-178.

[5] ZHANG Xiao-hong, L I Shi-qi, WANG J un-feng, L I Xun. Single object selective disassembly sequence planning based on ant colony algorithm [J]. Computer Integr ated Manufacturing Systems, 2007, 13(6):1109-1114.

[6] SONG Xiao-wen, PAN Xing-xing, FENG Kun, ZHOU Wei-dong. Complex product disassembly sequence planning oriented to defective parts [J]. Computer Integrated Manufacturing Systems, 2003, 19(6):1249-1255.

[7] CHENG Wen-yan, Wang Bo, JING Hui-ming. Researches about Modeling Hybrid Graph Model with Modularize Disassembly [J]. Science Technology and Engineering, 2008, 8(1):34-38.

[8] SHI Shi-cai, LI Rong, FU Yi-li, MA Yu-lin. Assembly sequence planning based on improved ant colony algorithm [J]. Computer Integrated Manufacturing Systems, 2010, 16(6):1189-1194. 